Religare, ISSN: 19826605, v.14, n.2, dezembro de 2017, p. 363-377.

\title{
O diálogo entre Aśtavakra e Janaka, no Tripura Rahasya, Sobre os Estados de Consciência
}

\author{
The dialogue between Astavakra and Janaka, in Tripura \\ Rahasya, on Conscience States
}

Eanes Torres Pereira ${ }^{1}$

\section{Resumo}

Este artigo apresenta uma tradução de partes do capítulo 16 do Tripura Rahasya seguidas de discussões e análises tendo como base conceitos apresentados no Yoga Sutra de Patanjali. O capítulo 16 do Tripura Rahasya trata dentre outros fatores do conceito de indizível na tradição indiana e de métodos para alcançar o estado em que é possível acessar o indizível, ou aquilo que não pode ser explicado por palavras. Argumentamos que o Rāja-Yoga de Patañjali é uma metodologia adequada para experimentar esse estado.

Palavras-chave: Rāja-Yoga, Tripura Rahasya, Estados de Consciência, Meditação.

\begin{abstract}
This paper presents a translation of parts of Chapter 16 of Tripura Rahasya followed by discussion and analysis based on concepts presented in the Patanjali's Yoga Sutra. Chapter 16 of Tripura Rahasya focuses on, among other factors, the concept of unutterable in the Indian tradition and methods to reach the state where you can access the unsayable, or what can not be explained by words. We argue that the Patanjali's Rāja-Yoga is an appropriate methodology to experience this state.
\end{abstract}

Keywords: Rāja-Yoga, Tripura Rahasya, Consciousness States, Meditation.

${ }^{1}$ Universidade Federal de Campina Grande, Centro de Engenharia Elétrica e Informática, Departamento de Sistemas e Computação. E-mail: eanes@computacao.ufcg.edu.br 
Religare, ISSN: 19826605, v.14, n.2, dezembro de 2017, p. 363-377.

\section{Introdução}

Este artigo tem como objetivo discutir as evidências de que um dos métodos apropriados para alcançar o estado de autorrealização mencionado por Dattatreya no Tripura Rahasya é o Rāja-Yoga de Patañjali conforme descrito no Yoga-Sūtra (MARTINS, 2012). O método do Rāja-Yoga é principalmente um método prático com experiências em primeira pessoa. Ou seja, o próprio praticante experimentará os resultados de suas práticas.

Neste artigo, o foco será predominantemente a percepção direta e experiencial de estados não usuais de consciência. Neste contexto, nos referimos a estados não usuais de consciência como sendo os estados experimentados durante práticas meditativas e que não são experimentados comumente por não praticantes de meditação.

A seguir, serão apresentados alguns personagens e conceitos do Hinduísmo que serão úteis ao entendimento das ideias apresentadas neste artigo. A começar por Dattatreya e alguns conceitos do Sānkkhya, tais como buddhi, ahamkāra e manas.

O Tripura Rahasya é um texto considerado tântrico que fornece tanto conhecimentos teóricos quanto conhecimentos práticos. Tais conhecimentos práticos podem ser chamados de śakti sādhanā (TIGUNAIT, 1993) e envolvem conhecimentos relacionados a cakras e kundalini. A śakti sādhanā não pode ser praticada adequadamente sem as instruções de um professor qualificado e, portanto, nenhuma técnica mencionada neste artigo deve ser praticada por conta própria. Mesmo porque as descrições contidas neste texto não são suficientes para um entendimento completo das técnicas.

Dattatreya é considerado, na tradição hinduísta um avatar de Viṣnu. A história de seu nascimento é narrada no Markandeya Purāṇa. Segundo a narração, o brâmane Kausika, embora não fosse um marido exemplar e se envolvesse com prostitutas e bebidas, possuía uma esposa exemplar. Certa vez, 
Religare, ISSN: 19826605, v.14, n.2, dezembro de 2017, p. 363-377.

Kausika estava doente e pediu que sua esposa o levasse para encontrar-se com uma cortesã. A esposa o tomou às costas, na escuridão da noite e levou-o à casa da cortesã. No entanto, no caminho, a esposa tropeçou num asceta poderoso acordando-o de seu sono. $\mathrm{O}$ asceta amaldiçou-a dizendo que ela e seu marido morreriam ao nascer do sol. Aflita, a esposa pediu que o sol não nascesse. Como era uma boa esposa, sua prece foi atendida. Porém, logo os devā começaram a se preocupar com o transtorno na ordem temporal com a interrupção do nascer do sol. Os devā consultaram Bramā que sugeriu que apenas outra esposa tão casta quanto a que fez o pedido poderia trazer os ciclos temporais ao seu ritmo normal, sendo que Anusuya seria uma boa candidata. Porém, ela deveria ser agradada com a concessão de alguns desejos. Dentre seus desejos, ela pediu que seus filhos fossem avatares de Bramā, Viṣnu e Śiva. Assim, Dattatreya nasceu de Anusuya como avatar de Viṣnu.

O texto Tripura Rahasya contém ensinamentos de Dattatreya a seu discípulo Parasurama. O texto é bastante complexo e contém uma variedade de histórias e ensinamentos. Em sua maior parte é composto por diálogos entre Dattatreya e Parasurama na forma de perguntas e respostas, sendo que, às vezes, Dattatreya responde aos questionamentos por meio de histórias ilustrativas. Uma das histórias narradas por Dattatreya é a história do príncipe Hemachuda e sua esposa Hemalekha. Há a ocorrência de histórias dentro de histórias, por exemplo, Hemalekha para dar ensinamentos a Hemachuda, conta histórias também. Este artigo tem como fundamento um dos diálogos entre dois personagens de uma das histórias contadas por Dattatreya: o diálogo entre Aśtavakra e Janaka. A versão do Tripura Rahasya utilizada para fundamentar este artigo é a tradução para o inglês de Saraswathi (2006) e a versão em sânscrito de Mishra (2016).

Logo no início do texto, o leitor se depara com o problema da possível impossibilidade de se ensinar algo que não pode ser conhecido:

TR. 16, 9-13 Por favor, explique, ó reservatório de compaixão, 
Religare, ISSN: 19826605, v.14, n.2, dezembro de 2017, p. 363-377.

como pode-se conhecer o incognoscível. Assim, questionado, Janaka, como que surpreso, respondeu: Ó tu, filho de um sábio, ouça-me! O fato é que isso não é inteiramente incognoscível, tampouco é inteiramente cognoscível. Como poderia um guru discorrer sobre aquilo que é inteiramente desconhecido? Se um guru pode ensinar, significa que ele conhece o que ele fala. Esse conhecimento (vedanam) é bastante fácil ou quase impossível de se alcançar: para aquele cuja visão está voltada para o interior, ele é facilmente alcançado; para aquele cuja visão está voltada para fora, esse conhecimento é extremamente difícil de se obter. ${ }^{2}$

O diálogo tem início com o questionamento do aluno sobre como é que ele vai entender algo que não pode ser entendido e mais, como alguém pode explicar algo que não pode ser conhecido. Esse algo incognoscível é o estado de autorrealização, um estado em que a mente usual como se conhece no ocidente não está funcionando em seu modo normal. Antes de continuarmos as discussões é necessário explicar alguns conceitos presentes no Tripura Rahasya. Em primeiro lugar, devemos considerar o conceito de Kleśa. O Yoga-Sūtra afirma: A raiz do KARMA está nessas perturbações (Kleśa) e produz nascimentos visíveis e invisíveis. (MARTINS, 2012, p. 141)

Segundo o Yoga-Sūtra (YS II, 12), o que produz o Karma é a ação movida por perturbações. Mas onde essas perturbações atuam? Por que o ser humano essencial (Puruṣa) seria perturbado visto que ele é apenas um observador passivo segundo o Sān்hya? Pois, segundo o dualismo Sān்khya, Puruṣa não é perturbado. Toda perturbação vem da Prakriti, o que inclui manas, budhi e ahamkara. Para respondermos a essas perguntas é necessário introduzir o conceito de órgãos internos sutis como definido no Sānkkhya-Kārikā (SK) de Iśvarakrșṇa : A função de cada um dos três (buddhi, ahamkāra, manas) é específica e não é comum. A causa comum da atividade dos órgãos internos é o conjunto dos cinco ventos (vāyu): prāṇa etc. (apāna, samāna, udāna, vyāna)... (MARTINS, 2012, p.167)

\footnotetext{
2 Tradução nossa
} 
Religare, ISSN: 19826605, v.14, n.2, dezembro de 2017, p. 363-377.

Segundo o Sān்khya-Kārikā, os órgãos sutis internos são manas, que corresponderia, de certa forma, ao que conhecemos como "mente" no ocidente. Porém, sendo mais apropriado dizer que manas corresponde à faculdade de pensar, ou ao processo descontrolado de fluxo de pensamentos que surgem como resultado da interação do ser com os objetos externos por meio dos órgãos de percepção (Jnanendriyas) e dos órgãos de ação (Karmendriyas). O segundo órgão sutil interno é buddhi, correspondendo em termos da cultura ocidental ao intelecto ou à racionalidade. A buddhi está conectada a manas no sentido de que é o que permite pensar sobre os pensamentos, ou raciocinar. Por fim, há o órgão sutil ahamkāra, que corresponderia ao ego. Mas sendo o princípio da individualidade, podemos dizer que o Ahamkāra corresponde ao conceito de identidade, às características que distinguem um indivíduo de outro. Segundo o Sānikhya, Purușa, o observador, aquele que é passivo, não possui forma, localização, nem atributos. Diferencia-se da Prakriti. O que ocorre naturalmente no ser humano é a influência das perturbações mentais que levam buddhi a identificar-se erroneamente com características de manas e ahamkāra, distanciando-se da Prakriti. Essa identificação errônea é uma das facetas do principal Kleśa, a ignorância, como mencionado no Yoga-Sūtra(YS):

YS II 3 As perturbações [KLEŚA] são cinco: ignorância [AVIDYĀ], individualismo [ASMITĀ], paixão [RĀGA], aversão [DVEȘA], apego [ABHINIVEŚA]. (MARTINS, 2012, pp. 140)

YS II 4 A ignorância é o campo de onde brotam todas as outras, sejam elas latentes ou vivas, bloqueadas ou vigorosas. (MARTINS, 2012, pp. 140)

Agora, podemos voltar ao questionamento feito a Janaka: como seria possível um mestre explicar a seu discípulo um estado em que não há identificação com pensamentos ou raciocínio? Como dizer o indizível? Para respondermos a esta pergunta devemos considerar o conceito de acintya, descrito por Martins (2013, Apud MONIER-WILLIAMS, 1979, p. 398) como a negação de cintya, que significa aquilo que deve ser pensado, concebido ou 
Religare, ISSN: 19826605, v.14, n.2, dezembro de 2017, p. 363-377.

imaginado. Segundo Martins (2013), o conceito de acintya permeia as escrituras do Hinduísmo porém não pode ser entendido de modo meramente racional. Para tratar esse tipo de conceito o pensamento indiano possui aspectos práticos. Sobre esses aspectos Martins (2013, p. 3) afirma:

O pensamento indiano não pode ser compreendido sem se levar em conta sua dimensão prática: ao falar sobre essa realidade incompreensível, as escrituras antigas indicam, ao mesmo tempo, a possibilidade de atingi-la. A filosofia é inseparável da prática (Yoga) destinada a permitir essas vivências.

Nas próximas seções, a afirmação de Martins (op. cit.) será de extrema importância para a argumentação deste artigo no sentido de que o Rāja-Yoga permite ao praticante a possibilidade de conhecer o incognoscível utilizando a experiência prática e não utilizando argumentações lógicas ou racionais. Seguindo essa linha de raciocínio o mestre poderia indicar determinadas práticas de Rāja-Yoga ao discípulo e por meio de trocas de experiências haveria a indicação "não isto" até que fosse possível o discípulo ter a experiência não necessariamente racional e lógica daquilo que não pode ser dito. Porém, deve ficar claro que os estados de consciência mencionados na Māṇ̣̂kya Upaniṣad e comentados por Martins (2013) não correspondem diretamente aos estados de conciência experimentados pelos praticantes de Rāja-Yoga.

Voltemos ao Tripura Rahasya e vejamos como Janaka responde à indagação de seu discípulo:

TR XVI 14 Somente aquilo que está além de toda percepção, investigação ou definição (anirūpyam) é de fato inteiramente incognoscível. Se algo pode ser percebido, investigado e definido de alguma maneira, então é cognoscível. Tudo aquilo que é visível e pode ser percebido aqui é, por essa razão, cognoscível. ${ }^{3}$

Janaka aponta para o fato de que tudo que pode ser acessado pelos órgãos dos sentidos ou pela investigação mental pode ser conhecido. Ou seja,

\footnotetext{
3 Tradução nossa.
} 
Religare, ISSN: 19826605, v.14, n.2, dezembro de 2017, p. 363-377.

por meio de um processo de eliminação (não isto) é possível chegar ao incognoscível. Porém, como se dá esse processo ainda não está claro nesse ponto do texto. Vejamos, então, a explicação seguinte.

TR XVI 15-21 Com sua inteligência, procure discernir aquilo pelo que os objetos são iluminados (bhāna-śaktih - lit. o "poder de percepção") que, embora destituído de visibilidade ou da possibilidade de se refletir sobre, é o suporte último de toda percepção. Saiba que isso é verdade, ó filho de um sábio! O que é cognoscível não é a consciência ou inteligência (vitti), mas "aquilo que não é auto luminoso" (svato yan na prakāśate). A consciência ou inteligência (vitti) é aquela pela qual os objetos são conhecidos; ela não pode ser o que ela é se ela se tornar o objeto de conhecimento. O que é inteligível deve sempre ser diferente da própria inteligência ou, de outro modo, não seria possível fazer-se conhecido por ela. Os objetos inteligíveis assumem diversas formas pelas quais são discernidos pela inteligência, mas a inteligência não pode jamais ser dividida em partes. Divisão é uma característica dos objetos cognoscíveis, não afetando a inteligência em tempo algum. Portanto, observe a Inteligência Absoluta ( esse é o termo usado no texto em inglês, no original em sânscrito o termo é buddhi) pela qual os fenômenos inteligíveis são iluminados após eliminar dela todas as diversas formas assumidas pelos objetos cognoscíveis. Assim como um espelho reproduz as formas dos objetos que reflete, também a Inteligência Abstrata (este é o termo usado no texto em inglês, no original em sânscrito o termo é citi) assume diferentes formas correspondentes aos objetos refletidos em si. Dessa forma, a Inteligência Abstrata (este é o termo usado no texto em inglês, no original em sânscrito o termo é vitti) pode ser conhecida pela remoção de todas as formas cognoscíveis. Ela não pode ser conhecida por si mesma, pois ela é o substrato universal de tudo. ${ }^{4}$

Aparentemente, Janaka está introduzindo uma técnica meditativa para seu discípulo: a observação da Inteligência Abstrata. Levando em consideração os conceitos do Sānikhya anteriormente descritos, podemos considerar a Inteligência Absoluta mencionada por Janaka como sendo o conceito de buddhi. No Sānikhya, a buddhi é o intelecto que raciocina sobre o que surge de manas, o modo comum desse raciocínio é buddhi identificar-se com manas como um 
Religare, ISSN: 19826605, v.14, n.2, dezembro de 2017, p. 363-377.

espelho que assume as formas dos objetos que lhe são expostos. Porém, o que surge de manas não é auto-luminoso, ou seja não tem existência própria, não faz sentido por si mesmo, pois falta algo que lhes dê sentido ou que raciocine sobre eles (como a buddhi). Assim, Janaka está indicando a seu discípulo que o processo para se conhecer a consciência subjacente, "que embora abstrata e afastada de objetos materiais", tem como um dos passos iniciais eliminar ou reduzir a influência dos objetos sobre o espelho, a influência de manas sobre a buddhi.

\section{Estados de consciência no hinduísmo}

Nas Upaniṣads, há um tema recorrente que é o dos estados que podem ser experimentados pelos seres humanos. A Māṇ̣ūkya Upaniṣad discorre, dentre outros assuntos, sobre os quatro estados de consciência: "(1) o estado desperto, (2) o estado de sono com sonhos, (3) o estado det sono sem sonhos... e o quarto estado (caturtha ou turìya)" (MARTINS, 2013). Além disso, segundo o Yoga-Sūtra, no estado desperto podem ser experimentados estados incomuns de consciência por meio de práticas conhecidas, de modo geral, como meditação. Vale ressaltar novamente que o estados descritos na Māṇ̣̂ukya Upanișad não são os mesmos estados alcançados pelo praticante de Rāja-Yoga. Para Patañjali, meditação corresponde à técnica/estado de dhyana. Na continuação do diálogo entre Janaka e seu discípulo, são introduzidos os conceitos de estados de consciência:

TR XVI 23-24 Não és o corpo (śarīram), a energia vital (prāṇa) ou a mente (manas) pois estes são impermanentes. O corpo é um agregado de elementos materiais (dhātu-nikaram); assim, como poderias ser essa forma? Além disso, no instante de cognição dos objetos o senso de "Eu" (aham) ultrapassa até mesmo o intelecto (dhī, buddhi) e assim também o ar vital (prāṇa) e a mente (manas). ${ }^{5}$

5 Tradução nossa. 
Religare, ISSN: 19826605, v.14, n.2, dezembro de 2017, p. 363-377.

No trecho transcrito anteriormente, surgem termos comuns no ocidente para representar diferentes níveis de identidade: self e ego. É claro que essas palavras são aproximações para termos do sânscrito. Podemos dizer que o self corresponde ao atman (purușa) e o ego corresponde predominantemente ao ahamkāra, porém podemos dizer que de modo geral corresponde ao conjunto manas-ahamkāra-buddhi, quando o indivíduo está sob o jugo do kleśa ignorância (avidyā). Outro termo que aparece pela nesse texto é samāahi, que pode significar união, junção. O samādhi é um dos oito membros do Rāja-Yoga, é um estado incomum de consciência que pode ser alcançado por meio de práticas específicas e será explicado em mais detalhes na Seção 3. Embora, na Māṇụūkya Upaniṣad se fale em 4 estados de consciência, podemos dizer que há sub-estados que podem ser experimentados durante o estado acordado, por exemplo os estados dhyana e samādhi. A partir da explicação de Janaka, se a buddhi é como um espelho que reflete objetos (que são apreendidos por órgãos externos como que por canais de informação) por intermédio de manas (órgão sutil que pode atuar como interno e externo), o Self (Atman) é a fonte de onde se origina a luz que torna os objetos visíveis no espelho. Assim, ao mesmo tempo que o Self emana luz, ele usa a reflexão da luz para estar consciente dos objetos externos. Apenas nos estados de sono profundo e samādhi, quando o "Eu" é não qualificado (livre das influências dos objetos externos e dos órgãos sutis internos) é que resta apenas a presença consciente que é o Self.

TR XVI 36-39 As percepções externas da mente são dependentes de duas condições. A primeira é a eliminação de outras percepções e a segunda é a fixação em um item particular de percepção. Se a mente for simplesmente afastada de outras percepções, a mente está em um estado indiferente, em que há ausência de qualquer tipo de percepção. Portanto, a concentração em um objeto particular é necessária para a percepção de coisas externas. Mas desde que a consciência é o Self e não separada da mente, a concentração sobre ela não é necessária para a sua realização. ${ }^{6}$

6 Tradução nossa. 
Religare, ISSN: 19826605, v.14, n.2, dezembro de 2017, p. 363-377.

No trecho anterior, são mencionadas duas condições para que a mente seja capaz de perceber fatores externos. Nota-se uma relação importante entre essas condições e dois membros do Rāja-Yoga: pratyāhara e dhārana. Os métodos de pratyāhara levam o praticante a desenvolver habilidades que o permitirão não ser afetado por fatores externos tais como: ruídos, calor, imagens, atritos no corpo, etc. Assim, pode-se dizer que essa prática é um primeiro passo rumo à eliminação de perturbações. Embora, inicialmente, as perturbações eliminadas sejam grosseiras. O objetivo principal dos métodos de dhārana é levar o praticante a ser capaz de concentrar sua mente em um único objeto, seja ele físico ou mental. Então, verifica-se que há um processo no Rāja-Yoga em que primeiro reduzem-se as perturbações por estímulos externos e, em seguida, exerce-se um forte domínio sobre a mente (manas) para domá-la e concentrá-la em um único objeto. Veremos nas próximas instruções de Janaka, que a concentração da mente no Self não é suficiente para apreender seu significado ou sua totalidade.

TR XVI 40-48 É suficiente que outras percepções (a saber, pensamentos) sejam eliminados da mente então o Self pode ser realizado. Se um homem quer escolher uma imagem particular dentre uma série de imagens que passam em sua frente, como reflexões em um espelho, ele deve afastar sua atenção do resto das imagens e fixá-la em uma imagem específica. Se, por outro lado, ele deseja ver o espaço refletido, é suficiente que afaste sua atenção das imagens e o espaço manifesta-se sem nenhuma atenção de sua parte, pois, o espaço é imanente em todo lugar e já está refletido lá. Contudo, ele permanece despercebido por causa que suas imagens interespaciais dominam a cena. Sendo o espaço o que dá suporte a tudo e imanente em tudo, torna-se manifesto somente se a atenção desviar-se do panorama. Do mesmo modo, a consciência (citi) é o que dá suporte à tudo e é imanente em tudo e sempre permanece perfeita como o espaço, permeando a mente também. O desvio da atenção de todos os itens é tudo que é necessário [para a Autorrealização, implícita aqui e antes referida como krtārthata - realização]. Ou você diz que o Autoiluminante (citi) pode sempre estar ausente de qualquer canto ou recanto? Não pode, de fato, haver nenhum momento ou ponto em que a consciência esteja ausente. Sua ausência significa a ausência deles também. Portanto, a consciência do Self (cid-ātmāvabhāse - lit. o brilho do ātman) 
Religare, ISSN: 19826605, v.14, n.2, dezembro de 2017, p. 363-377.

torna-se manifesta pelo mero desvio da atenção das coisas e pensamentos. A realização do Self requer pureza absoluta somente e nenhuma concentração mental. Por essa razão, o Self é chamado de incognoscível (significando não cogniscível objetivamente). Portanto, também foi dito que a única necessidade para Autorrealização (tattva-jñāna - lit. conhecimento da verdade) é pureza mental. A única impureza da mente é o pensamento. Torná-la livre de pensamentos é mantê-la pura. ${ }^{7}$

Nessa etapa, Janaka está explicando o procedimento pelo qual é possível alcançar a autorrealização. O princípio fundamental é dominar e controlar a atenção para ser capaz de desvia-la daquilo que não é o Self (as coisas e pensamentos). Ao mesmo tempo que Janaka afirma a necessidade de controlar a atenção, ele também afirma que não é necessário concentração mental. Deve ficar claro que manas nunca cessa, ou seja, os pensamentos e a percepção das coisas continuam existindo, porém quando a realização do Self é atingida, o que cessa é a identificação do observador (da atenção) com manas.

Um questionamento que o leitor do Tripura Rahasya poderia fazer está relacionado ao procedimento ou metodologia que pode ser seguido para alcançar o estado de realização do Self. $\mathrm{Na}$ próxima seção, apresentamos o Rāja-Yoga como sistematizado por Patañjali como um método apropriado para tal fim e que está de acordo com os ensinamentos do Tripura Rahasya.

\section{O Rāja-Yoga como método para alcançar a autorrealização}

O Rāja-Yoga de Patañjali também é conhecido como Ashtanga Yoga por suas técnicas poderem ser agrupadas em oito partes: as abstenções, as observâncias, as posturas, a concentração, a meditação e a união (MARTINS, 2012, p. 74). As três últimas partes são chamadas de membros internos. Embora sejam mencionadas técnicas com exercícios respiratórios e ásanas, Patañjali enfatiza as técnicas internas no Yoga-Sūtra. De modo geral, a metodologia de técnicas internas descrita por Patañjali é executada do seguinte modo:

7 Tradução nossa. 
Religare, ISSN: 19826605, v.14, n.2, dezembro de 2017, p. 363-377.

1. O praticante realiza abstenção dos sentidos: desconsidera (ou se afasta de) todas as percepções advindas por visão, audição, tato, olfato, etc. $\mathrm{O}$ praticante deve treinar sua habilidade de não ser perturbado por fatores externos.

2. O praticante concentra-se em algum objeto. Essa concentração pode ser realizada tanto em objetos físicos externos, quanto em objetos mentais, percepções, ou mantras.

3. O praticante realiza o estado meditativo propriamente dito (dhyana). Esse estado pode ser caracterizado por fenômenos mentais incomuns no dia a dia de não praticantes de meditação. 4. Por fim, o praticante atinge Yoga. No contexto da metodologia, o estado de união é chamado de samādhi.

Um fator muito importante nas práticas espirituais originadas na Índia é a ênfase dada aos exercícios práticos, que podem ser chamados coletivamente de Yoga. Assim, pode-se dizer que a experiência prática de estados de consciência não usuais pode funcionar como evidência empírica para as hipóteses que fundamentam aspectos que de outra forma exigiriam crença.

Goleman (1988, p. 71) afirma que o Yoga-Sūtra de Patañjali é o texto que pode ser chamado de "oficial" sobre Yoga. Um aspecto importante sobre o qual Goleman chama a atenção é que os 3 membros internos do Yoga (dharana, dhyana e samādhi) formam conjuntamente o estado conhecido como samyama. Esse é um aspecto importante que deve ser ressaltado, pois há relatos de praticantes que evidenciam que, principalmente, no início da vida de prática, o samādhi não ocorre de modo constante, mas sim de modo alternado com os outros dois estados mencionados.

Uma referência muito importante para entendermos do que se trata este estado conhecido como samādhi são os bhasyas (comentários) da tradição indiana. No caso do Yoga Sutra, um comentário muito famoso é o Yoga-Darsána com comentários de Vyasa (JHA, 1935a).

Segundo Jha (1935b), a meditação (samādhi) é de dois tipos:

- $\quad$ Salambana ou Sabija (consciente ou concreta): o objeto sobre o qual se medita é apreendido de forma distinta ou direta;

- Niralamba ou Nirbija (inconsciente ou abstrata): ocorre uma inibição completa de todas as funções da mente, em que o agente perde toda a consciência das coisas fora dele, isto é ele 
Religare, ISSN: 19826605, v.14, n.2, dezembro de 2017, p. 363-377.

está literalmente auto-consciente (consciente da realidade absoluta e imutável).

Para o contexto deste artigo, o segundo estado (Nirbija) é o que nos interessa, pois é neste estado que o praticante pode experimentar a realidade última que não pode ser expressa por palavras e que Janaka tanto deseja entender. Observando o estado meditativo do Yoga a partir desse ponto de vista, verificamos que o Rāja-Yoga fornece uma metodologia empírica para produzir evidências que comprovam as hipóteses que não podem ser comprovadas por meio de deduções, induções ou raciocínio lógico. Pois, o objetivo é conhecer o incogniscível, e o que é incogniscível não pode ser acessado pelo raciocínio usual. Pode ser acessado apenas pela percepção direta.

As evidências empíricas fornecidas pela prática de Rāja-Yoga podem ser questionadas por cientistas experimentais, pois

a evidência experimental, para ser encarada como evidência empírica, tinha de ser verificável - acessível a inúmeros observadores competentes. Mas os processos mentais só podem ser observados internamente. Não podem ser detectados por nenhum observador externo ou por nenhum dos instrumentos da ciência, que são concebidos para medir todos os tipos conhecidos de realidades físicas. (WALLACE, 2011)

No entanto, a evidência mais poderosa é a obtida por experiência direta. Além disso, quando diversos praticantes compartilham experiências semelhantes a evidência se torna ainda mais forte. Mesmo sendo experiências em primeira pessoa, tais experiências são comprovadas por praticantes das mais diversas culturas e condições sociais o que aumenta a força das evidências. Enfim, para o praticante, não haverá dúvidas sobre a veracidade do que ele está vivenciando.

\section{Considerações finais}

Neste artigo, delineamos as principais ideias necesárias para o 
Religare, ISSN: 19826605, v.14, n.2, dezembro de 2017, p. 363-377.

entendimento dos membros internos do Rāja-Yoga de Patañjali. Além disso, apresentamos as conexões existentes entre o Rāja-Yoga e os ensinamentos de Dattatreya presentes no capítulo 16 do Tripura Rahasya. Por fim, discutimos as evidências de que o Rāja-Yoga é uma metodologia apropriada para alcançar o estado de autorrealização descrito por Dattatreya. Os resultados obtidos por meio das práticas de Rāja-Yoga são predominantemente empíricos e compostos por experiências em primeira pessoa.

\section{Referências}

ELIADE, Mircea. Yoga: Immortality and Freedom. Princeton University Press. 2009.

FEUERSTEIN, Georg. The Yoga Tradition: Its History, Literature, Philosophy and Practice. Hohm Press, 1998.

FEUERSTEIN, Georg. Tantra the Path of Ecstasy. Shambala Publications, 1998.

FOX, Kieran C. R.; NIJEBOER, Savannah; DIXON, Mattehew L.; FLOMAN, James L.; ELLAMIL, Melissa; RUMAK, Samuel P.; SEDLMEIER, Peter.; CHRISTOFF, Kalina. Is meditation associated with altered brain structure? A systematic review and meta-analysis of morphometric neuroimaging in meditation practitioners. Neuroscience Behavioral Review. n. 43, p. 48 - 73. 2014.

GOLEMAN, Daniel. The Meditative Mind: The Varieties of Meditative Experience. Tarcher Putnam, 1988.

JHA, GANGANATHA. The Yoga-Darśana: The sutras of Patañjali with the bhasya of Vyasa. Published for Bombay Theosophical Publication Fund by Rajaram Tukaram Tatya, 1935.

MARTINS, Roberto de Andrade. O Yoga Tradicional de Patañjali: O Rāja-Yoga segundo o Yoga-Sūtra e outros textos indianos clássicos. Shri Yoga Devi, São Paulo, 2012.

MARTINS, Roberto de Andrade. O indizível no pensamento indiano: a sabedoria que ultrapassa os conceitos. p. 85 - 102, in: SANTOS, João Marcos Leitão (org.). Religião, a herança das crenças e as diversidades de crer. Campina Grande, Editora da Universidade Federal de Campina Grande, 2013.

MISHRA, Acharya Jagadish Chandra. Tripura Rahasya - Gyan Khand. Disponível em: https:/www.scribd.com/doc/157759786/Tripura-Rahasya-GyanKhand-Acharya-Jagadish-Chandra-Mishra . Acessado em 04 de outubro de 2016.

SARASWATHI, Swami S. R. Tripura Rahasya: The mistery beyond trinity. Sudarsan Graphics. 7 edição, 2006.

MARKANDEYA Purāṇa, capítulo 16. Data do último acesso: 07 de dezembro 
Religare, ISSN: 19826605, v.14, n.2, dezembro de 2017, p. 363-377.

de 2015.

Disponível

em:

http://www.ramayana.pushpak.de/pdf/markandeya en.pdf

TIGUNAIT, Pandit R., Śakti Sadhana: steps to samadhi, a translation of the Tripura Rahasya. Himalayan Institute, 1993.

WALLACE, Alan B. Mente em equilíbrio: A meditação na ciência, no Budismo e no Cristianismo. Cultrix, 2011. 